\title{
Distressed but happy: health workers and volunteers during the COVID-19 pandemic
}

\author{
Tiantian $\mathrm{Mo}^{1} \cdot$ Kristin Layous $^{2} \cdot$ Xinyue Zhou $^{1}$ (D) $\cdot$ Constantine Sedikides $^{3}$
}

Accepted: 24 February 2021 / Published online: 19 May 2021

(c) The Author(s), under exclusive licence to Springer-Verlag GmbH Germany, part of Springer Nature 2021

\begin{abstract}
During the COVID-19 outbreak, many people rose to the occasion by engaging in volunteerism and health work. We conducted two nationwide surveys in the United States $(n=2931)$ and China $(n=2793)$ assessing volunteers' and health workers' levels of mental distress and happiness. In spite of data being collected at different phases of the COVID-19 outbreak and across two different cultures, the results converged. Volunteers and health workers reported higher mental distress (e.g., depression, anxiety, somatization) than the comparison group. However, volunteers and health workers also reported more happiness than the comparison group. More importantly, in a follow-up in China $(n=1914)$ one month later, health workers still reported heightened happiness but were no longer more distressed than the comparison group. The changes in distress were partially mediated by happiness at the first time point, pointing to the potential role of happiness in coping with distress. In sum, the emotional landscape of volunteers and health workers was complicatedthey experienced higher distress but also higher happiness than comparison groups. Future research would do well to include longer follow-up periods to examine how experiencing happiness during highly stressful situations predicts mental health over time.
\end{abstract}

Keywords Distress $\cdot$ Happiness $\cdot$ Health workers $\cdot$ Volunteers $\cdot$ COVID-19

Xinyue Zhou

xinyuezhou@zju.edu.cn

Tiantian Mo

tiantianmo@zju.edu.cn

Kristin Layous

kristin.layous@csueastbay.edu

Constantine Sedikides

cs2@soton.ac.uk

1 School of Management, Zhejiang University, Hangzhou 310058, Zhejiang Province, China

2 Department of Psychology, California State University, East Bay, USA

3 School of Psychology, University of Southampton, Southampton, UK 


\section{Introduction}

Since the outbreak of the COVID-19 pandemic, many people have gone beyond the call of duty to assist others while putting themselves in harm's way. For example, in China, 42,000 health workers offered their services in Wuhan, the epicenter of the outbreak (National Health Commission of the People's Republic of China, 2020). Also, in the UK, just hours after the National Health Service issued a request for a quarter million volunteers, more than 170,000 individuals had signed up to help (World Economic Forum, 2020). It seems that the pandemic triggered a wave of prosociality.

However, health workers and volunteers put themselves at risk, not only because they are more likely to be infected, but also because the extreme working conditions (e.g., long hours, uncertain circumstances) undermine mental health. A recent study focused on the mental health of 1257 health workers tending to COVID-19 patients in 34 hospitals in China (Lai et al., 2020). An alarming proportion of them experienced symptoms of insomnia (34\%), anxiety (45\%), depression (50\%), and distress (71.5\%). Studies conducted during previous virus outbreaks, such as SARS and MERS (Bai et al., 2004; Lee et al., 2007, 2018; Maunder et al., 2003), produced similar results.

There are several reasons that can account for health workers' and volunteers' mental distress. Burdened with the emotional strain of prolonged hours looking after others' needs, health workers and volunteers are more likely to experience fatigue and burnout (Maslach et al., 2001). Given that patients are isolated from family and friends, health workers try to provide patients with emotional support, as well as physical support, adding to their workload and exhaustion (Liu et al., 2020). Additionally, health workers are likely to be exposed to traumatic events such as witnessing patients' deaths or informing families that their beloved died without them present. Further, especially at the beginning of the pandemic, health workers lacked adequate personal protective equipment, thus spending long hours in the same equipment, avoiding eating and drinking to forestall bathroom breaks, and living in fear of infection of themselves and their families (Liu et al., 2020; Maunder et al., 2003).

However, even though the mental health literature points to mental distress among health workers and volunteers, the predominant view in another stream of literature is that engaging in prosocial behavior contributes to psychological wellbeing or happiness (Aknin et al., 2012; Alden \& Trew, 2013; Chancellor et al., 2018; Layous et al., 2013; Lyubomirsky et al., 2005; Mongrain et al., 2011; Nelson et al., 2014; Otake et al., 2006; Pressman et al., 2014). In a large-scale study, using two waves of panel data, researchers found that volunteering is linked to increases in well-being (i.e., happiness, life satisfaction, self-esteem, sense of control, physical health; Thoits \& Hewitt, 2001). Further, volunteering is associated with distress reduction. For example, volunteering relates to a reduction of depressive symptoms and buffering of distress caused by exposure to stressful life events in the past 12 months (Rietschlin, 1998). Importantly, none of these studies address the relationship between helping and happiness in situations similar 
to the current pandemic_-during which helping puts the helper at great personal risk.

Taken together, health work and volunteering may confer both psychological costs (e.g., mental distress) and psychological benefits (e.g., happiness). We address this dual character of helping in two cross-sectional studies, carried out in the US (Study 1) and China (Study 2). We hypothesized that helping during the pandemic relates positively to volunteers' and health workers' mental distress, but also to their happiness. In addition, in Study 2, we collected data one month after the crosssectional study to explore whether health workers' happiness and distress endured. Finally, in line with theory on the restorative function of positive emotions during the stress process (Folkman, 2008), we explored whether relatively greater happiness at the first time point of Study 2 predicted lower distress at the second. Both studies were approved by the Department of Psychology, University of [BLINDED], and informed consent was obtained prior to participation.

\section{Study 1}

In this cross-sectional study, we examined the association between volunteerism and mental distress and happiness. We relied on a broader survey of U.S. residents regarding responses to the COVID-19 outbreak.

\section{Method}

\section{Participants}

The survey was carried out by the Institute of Psychology, Chinese Academy of Sciences between March 20-26, 2020 when the number of infections in the US was rising. We only analyzed measures relevant to our theoretical interests.

The survey, which was conducted via Amazon Mechanical Turk, tested 2957 participants from all 50 U.S. states. Of them, 26 failed the attention check (e.g., responded wrongly to the instruction "please chose the number 7"), resulting in a sample of 2931 participants (56.53\% women; age in years: range 18-82, $M=38.19$, $S D=12.91$; ethnicity: $76.90 \%$ Whites, $12.18 \%$ African Americans, $7.34 \%$ Asians, 5.46\% Latino/Hispanic Americans, 2.32\% Native Americans, 1.09\% Others). Additional analyses involving the 26 excluded participants produced virtually identical results.

\section{Measures}

\section{Volunteering}

Participants were asked if they volunteered in the past two weeks $(0=n o, 1=y e s)$. Among them, 28.93\% $(n=848)$ indicated that they volunteered. 


\section{Mental distress}

Participants completed the 18-item Brief Symptom Inventory (BSI; Derogatis, 2001). They indicated the extent to which they felt depressed, anxious, or expressed somatic complaints ( six items each) over the past week $(0=$ not at all, $4=$ extremely). As per common practice (Cohen, 2014; Meachen et al., 2008; Petkus et al., 2010), we computed an overall score, forming an index of mental distress (Cronbach's $\alpha=0.97$ ), which is referred to as the Global Severity Index (GSI). Separate analyses on the three subscales produced results very similar to the reported ones.

\section{Happiness}

Participants responded to three items (Cronbach's $\alpha=0.89$ ): (a) I consider myself $\ldots 1=$ not a very happy person; $7=a$ very happy person; (b) Compared with my peers, I consider myself ... 1= much less happy, 7=much more happy; and (c) I think my life is ... 1=not meaningful at all, $7=$ very meaningful. The first two items were derived from the subjective happiness scale (Lyubomirsky \& Lepper, 1999), although, for brevity, the second item was phrased as "... my peers ..." instead of "... most of my peers ...". The third item was added to expand the conceptual scope of happiness (Ryff, 1989). Analyses involving only the first two items yielded results very similar to the reported ones.

\section{Results}

Volunteers $(M=28.06,95 \% \mathrm{CI}=[26.65,29.47])$ reported more mental distress (i.e., higher GSI) than non-volunteers $(M=13.67,95 \% \mathrm{CI}=[13.08,14.26]), F(1$, $2929)=481.33, p<.001$ (Fig. 1, left panel). We also computed prevalence (i.e.,
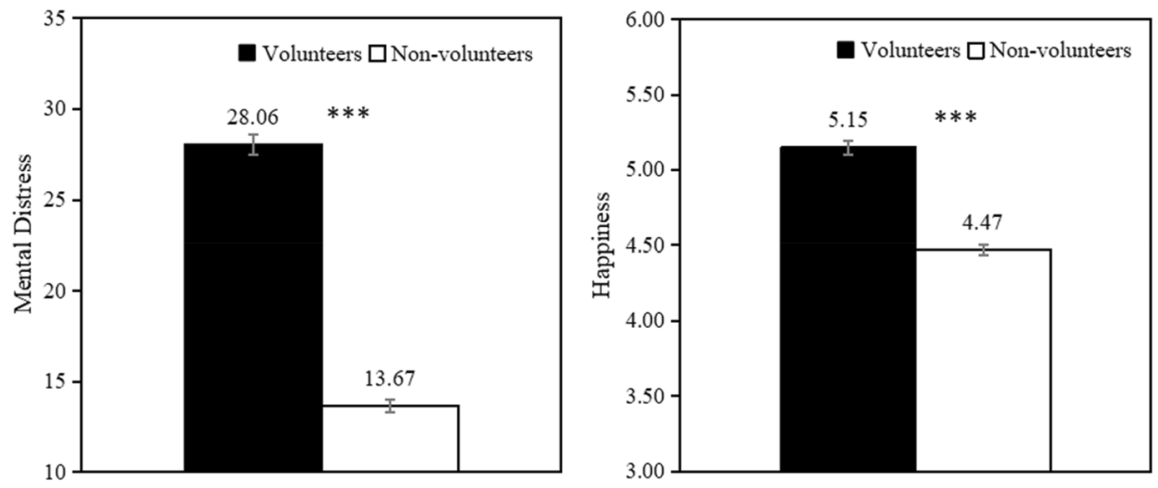

Fig. 1 Mental distress and happiness in Study $1(N=2931)$. The black columns represent the volunteers and the white columns represent the non-volunteers. Mental distress is a continuous variable ranging from 0 to 72 . Happiness is a continuous variable ranging from 1 to 7 . Error bars represent \pm 1 standard error. $* * * p<.001$ 
proportion of participants under mental distress) based on the suggested GSI cutoff score (Derogatis 2001). Prevalence among volunteers was $67.81 \%, 95 \% \mathrm{CI}=$ $[64.66 \%, 70.96 \%]$, whereas prevalence among non-volunteers was $43.93 \%, 95 \%$ $\mathrm{CI}=[41.79 \%, 46.06 \%]$ (Fig. 2). However, in spite of feeling more distressed, volunteers $(M=5.15,95 \% \mathrm{CI}=[5.06,5.23])$ also reported feeling happier than non-volunteers $(\mathrm{M}=4.47,95 \% \mathrm{CI}=[4.41,4.53]), F(1,2929)=152.73, p<.001$ (Fig. 1, right panel). We included the effects of ethnicity in Supplementary Material.

Interestingly, although mental distress was negatively associated with happiness among non-volunteers $(r=-.42, t(2081)=-20.87, p<.001,95 \% \mathrm{CI}=$ $[-0.46,-0.38])$, it was only slightly and positively associated with happiness among volunteers $(r=.07, t(846)=1.88, p=.060,95 \% \mathrm{CI}=[-0.003,0.13])$. Overall, happiness was negatively associated with mental distress $(r=-.13$, $t(2929)=-7.00, p<.001,95 \% \mathrm{CI}=[-0.16,-0.09])$.

\section{Discussion}

The results are consistent with our hypothesis. Volunteers, although more mentally distressed, also reported being happier. Importantly, the participants were not necessarily directly involved with efforts toward addressing the pandemic, but were simply volunteering while the pandemic was taking place. In Study 2, we address this limitation by exploring health workers in China.

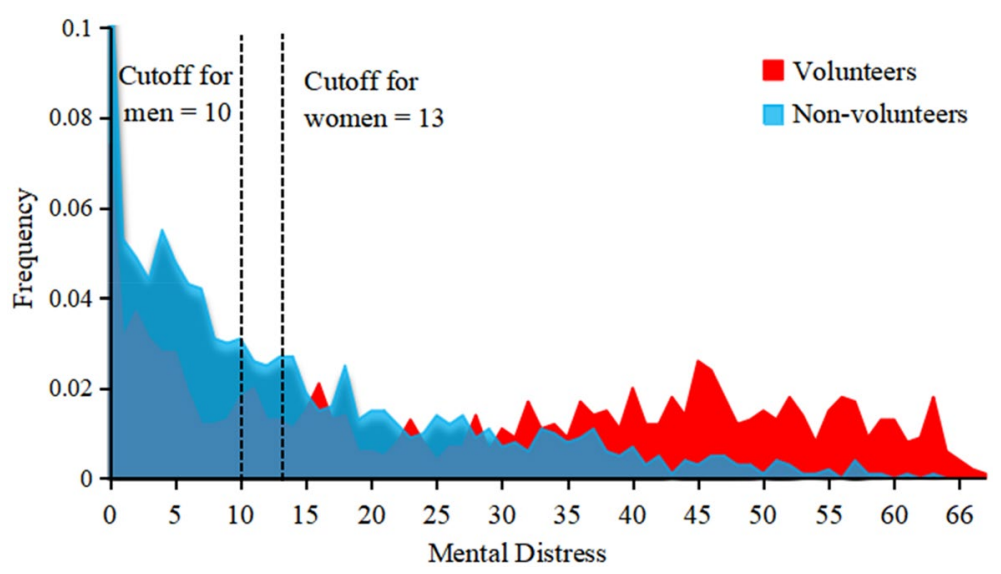

Fig. 2 Volunteers suffered more mental distress than non-volunteers in Study $1(N=2931)$. The X-axis represents mental distress scores as indexed by GSI, and the Y-axis represents the percentage of participants who had a corresponding GSI score. The red area represents volunteers $(n=848)$ and the blue area represents non-volunteers $(n=2083)$. The suggested cutoff for clinically significant mental distress is 10 for men and 13 for women participants. The area to the right of the cutoff score is the prevalence. (Color figure online) 


\section{Study 2}

In Study 2, we focused on health workers. The study had a cross-sectional component and a longitudinal component. In the cross-sectional component, we tested the replicability of Study 1 findings in another culture (China) and with a different measure of happiness. In the longitudinal component, we explored whether happiness and distress had changed one month after the first assessment and whether relatively greater happiness at the first time point predicted relatively lower distress at the second.

\section{Method}

\section{Participants}

We capitalized on a broader survey of Chinese residents regarding responses to the COVID-19 outbreak. The survey was carried out by the Institute of Psychology, Chinese Academy of Sciences. At Time 1, they tested 2854 participants from 31 of the 34 Chinese provinces (all but Hongkong, Macau, and Taiwan) via credamo. com and wjx.com (March 8-15, 2020; Time 1). We excluded 24 participants, due to a failed attention check (same as in Study 1) and another 37 for being under the age of 18. The final sample consisted of 2793 participants. The results remained the same when we added the 61 excluded participants in the analyses. The final sample comprised 461 health workers $(60.95 \%$ women; age in years: range 18-58, $M=29.60, S D=6.44 ; 86.76 \%$ doctors or nurses; $13.24 \%$ administrative, support staff, or other) and 2332 persons in various occupations (e.g., accountants, teachers; $52.19 \%$ women; age in years: range $18-67, M=28.44, S D=8.13$ ).

Between April 8-10, 2020, the survey administrators asked the 2186 individuals who participated in Time 1 via credamo.com to take part in a follow-up (Time 2; given that this platform kept detailed contact information). Of them, 1914 responded. No one failed the attention check, so we had 1914 valid cases. The final sample included 367 health workers (61.04\% women; age in years: range 19-56, $M=30.21, S D=5.80 ; 89.10 \%$ doctors or nurses; $10.90 \%$ administrative, support staff, or other) and 1547 persons from other non-frontline occupations $(49.77 \%$ women; age in years: range $18-67, M=28.45, S D=6.64)$.

\section{Measures}

Participants completed the same measure of mental distress as in Study 1 (Cronbach's $\alpha=0.93$ ). Again, separate analyses on the three subscales yielded results very similar to the reported ones. In addition, at both time points, participants indicated their happiness by responding to two items: "For the past week, how happy has your life been?" and "For the past week, how meaningful has your life been? $(1=n o t$ at all, $7=$ very much; Cronbach's $\alpha=0.87)$. We included the complete measures of two studies in Supplementary Material. The measures of mental distress has been 
validated in English (Derogatis 2001) and Chinese (Wang et al. 2012, 2013; Wang \& Mallinckrodt 2006). The measures of happiness has been validated only in English (Lyubomirsky \& Lepper 1999; Ryff, 1989).

\section{Results}

\section{Cross-sectional (Time 1)}

Health workers $(M=9.20,95 \% \mathrm{CI}=[8.26,10.13])$ reported more mental distress than the comparison group $(M=7.58,95 \% \mathrm{CI}=[7.21,7.96]), F(1,2791)=11.28$, $p=.001$ (Fig. 3, left panel). Prevalence was 27.77\%, 95\% CI $=[23.66 \%, 31.87 \%]$ among health workers, and $23.76 \%, 95 \% \mathrm{CI}=[22.03 \%, 25.49 \%]$ in the comparison group (Fig. 4).

Importantly, in spite of feeling more distressed, health workers $(M=5.23,95 \% \mathrm{CI}$ $=[5.12,5.35])$ also reported feeling happier than the comparison group $(M=5.02$, $95 \% \mathrm{CI}=[4.96,5.07]), F(1,2791)=9.32, p=.002$ (Fig. 3, right panel).

As in Study 1, mental distress was negatively associated with happiness in the comparison group $(r=-.36, t(2330)=-18.49, p<.001,95 \% \mathrm{CI}=[-0.40,-$ $0.32])$, and among health workers, although the effect was weaker $(r=-.30, t(459)$ $=-6.76, p<.001,95 \% \mathrm{CI}=[-0.39,-0.21])$. Overall, mental distress and happiness were negatively associated $(r=-.34, t(2791)=-19.26, p<.001,95 \% \mathrm{CI}=$ $[-0.38,-0.31])$.

\section{Cross-sectional (Time 2)}

At the follow-up time point, health workers $(M=5.61,95 \% \mathrm{CI}=[5.51,5.71])$ again reported greater happiness than the comparison group $(M=5.38,95 \% \mathrm{CI}=[5.32$,
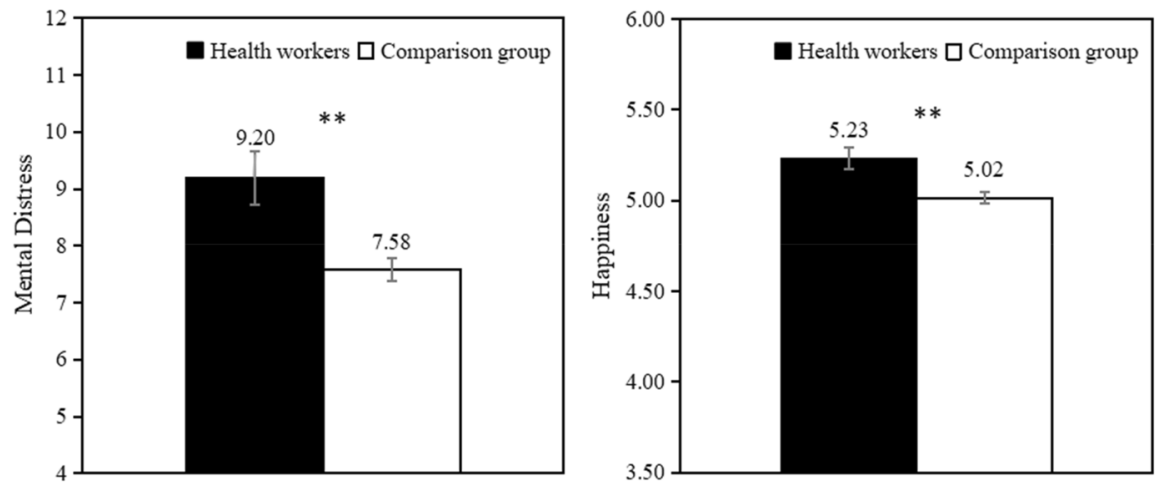

Fig. 3 Mental distress and happiness in Study 2 Time $1(N=2793)$. The black columns represent the health workers and the white columns represent the comparison group. Mental distress is a continuous variable ranging from 0 to 72 . Happiness is a continuous variable ranging from 1 to 7 . Error bars represent \pm 1 standard error. $* * p<.010$ 


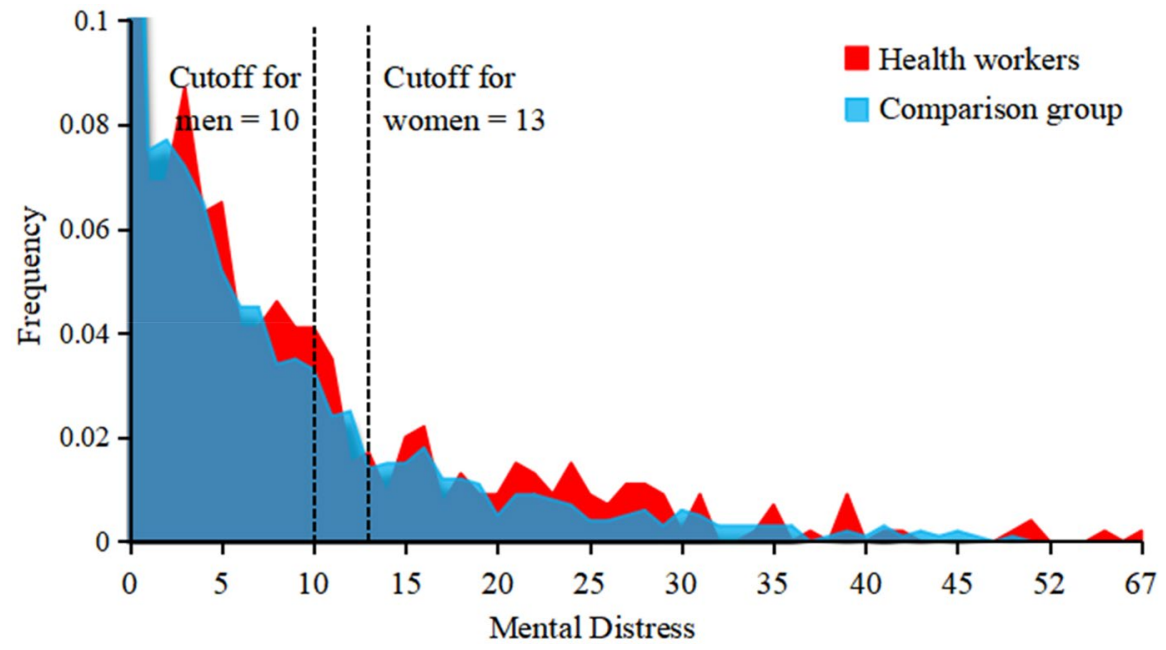

Fig. 4 Health workers suffered more mental distress than the comparison group in Study 2 Time 1 $(N=2793)$. The X-axis reflects mental distress scores as indexed by GSI, whereas the Y-axis reflects the percentage of participants who had a corresponding GSI score. The red area represents health workers $(n=461)$ and the blue area represents the comparison group $(n=2332)$. The suggested cutoff for clinically significant mental distress is 10 for men and 13 for women participants. The area to the right of the cutoff score is the prevalence. (Color figure online)

5.44] $), F(1,1912)=10.67, p=.001$. However, health workers $(M=8.76,95 \% \mathrm{CI}=$ $[7.70,9.82])$ were no longer more mentally distressed than the comparison group $(M=9.15,95 \% \mathrm{CI}=[8.62,9.68]), F(1,1912)=0.40, p=.527$. Prevalence was $24.80 \%, 95 \% \mathrm{CI}=[20.36 \%, 29.23 \%]$ among health workers, and $28.05 \%, 95 \% \mathrm{CI}=$ $[25.81 \%, 30.30 \%]$ in the comparison group.

\section{Longitudinal (Time 1 and Time 2)}

\section{Repeated measures analyses}

We conducted $2 \times 2$ mixed model analysis with one repeated measure factor (happiness) and one between-subjects factor (health workers vs. comparison group). There was a significant difference between Time 1 happiness $(M=5.13,95 \%$ $\mathrm{CI}=[5.07,5.19])$ and Time 2 happiness $(M=5.43,95 \% \mathrm{CI}=[5.37,5.48]), F(1$, $1912)=73.37, p<.001, \eta_{p}^{2}=0.037$. One month later, all participants reported being happier. Moreover, health workers $(M=5.46,95 \% \mathrm{CI}=[5.34,5.57])$ were happier than the comparison group $(M=5.24,95 \% \mathrm{CI}=[5.18,5.29]), F(1,1912)=11.49$, $p=.001, \eta_{p}^{2}=0.006$. The interaction was not significant, $F(1,1912)=0.03, p=.856$, $\eta_{p}^{2}<0.001$. Health workers and the comparison group showed similar increases in happiness.

We conducted the same $2 \times 2$ mixed model analysis with one repeated factor (mental distress) and one between-subjects factor (health workers vs. comparison 
group). There was no significant difference between Time 1 and Time 2 mental distress, $F(1,1912)=1.18, p=.277, \eta_{p}^{2}=0.001$. Also, health workers did not differ from the comparison group on mental distress, $F(1,1912)=1.05, p=.305$, $\eta_{p}^{2}=0.001$. However, the interaction was significant, $F(1,1912)=15.27, p<.001$, $\eta_{p}^{2}=0.008$ (Fig. 5). Simple effect analyses showed that, after one month, mental distress was significantly reduced among health workers $\left(M_{\text {Time1 symptoms }}=\right.$ 9.97, $95 \% \mathrm{CI}=[8.96,10.98], M_{\text {Time2 symptoms }}=8.76,95 \% \mathrm{CI}=[7.68,9.84], F(1$, $\left.1912)=7.72, p=.006, \eta_{p}^{2}=0.004\right)$, but significantly increased in the comparison group $\left(M_{\text {Time1 symptoms }}=8.47,95 \% \mathrm{CI}=[7.97,8.96], M_{\text {Time2 symptoms }}=9.15\right.$, $\left.95 \% \mathrm{CI}=[8.62,9.68], F(1,1912)=10.37, p=.001, \eta_{p}^{2}=0.005\right)$ (Fig. 6). We also explored these relationships by level of outbreak severity and included the results in Supplementary Material.

\section{Mediation analyses}

In a mediation analysis with 5,000 bootstrap samples (Hayes 2018; PROCESS Version 3.4, Model 4), we found a significant indirect effect of health work (vs. comparison group) on Time 2 distress via Time 1 happiness, $b=-0.34$, $S E=0.09,95 \%$ CI $[-0.54,-0.18]$ (adjusting for Time 1 distress; Fig. 7). We also found a significant direct effect of health work on Time 2 distress, indicating that Time 1 happiness did not explain the entire reduction in distress among health workers. We also conducted cross-sectional mediation analyses in Study 1 and Study 2 Time 1, and included the results in Supplementary Material.

After controlling for age, gender, and religious belief (only in Study 1), our main results in Studies 1 and 2 remained significant. We also analyzed how the severity of outbreaks in different regions affected participants' subjective perceptions. We included the results of Studies 1 and 2 in Supplementary Material.

(a) Happiness

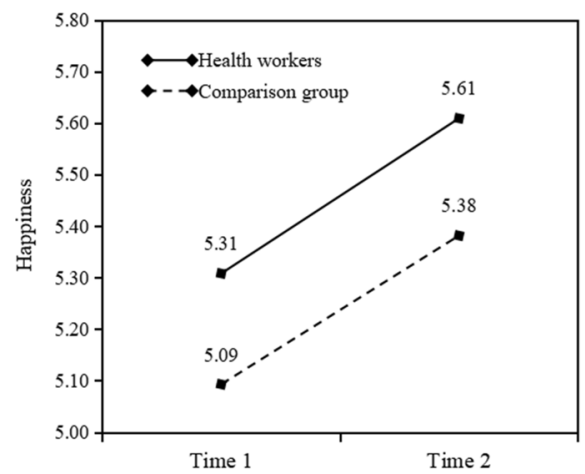

(b) Mental Distress

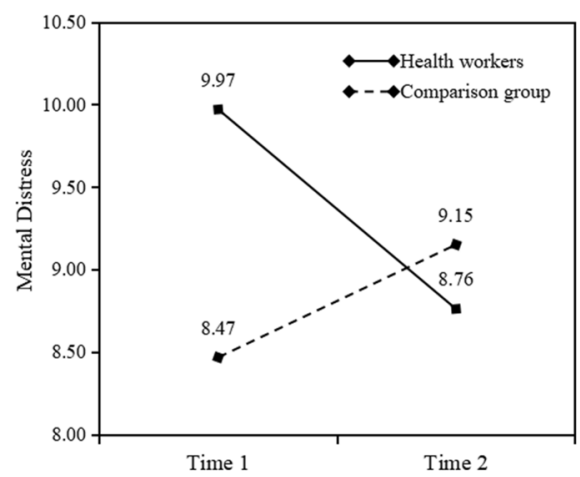

Fig. 5 Happiness and mental distress in Time 1 and Time 2 in Study $2(N=1914)$. The black solid lines represent health workers and the black dotted lines represent the comparison group. Happiness is a continuous variable ranging from 1 to 7 . Mental distress is a continuous variable ranging from 0 to 72 
(a) Health workers: Mental Distress

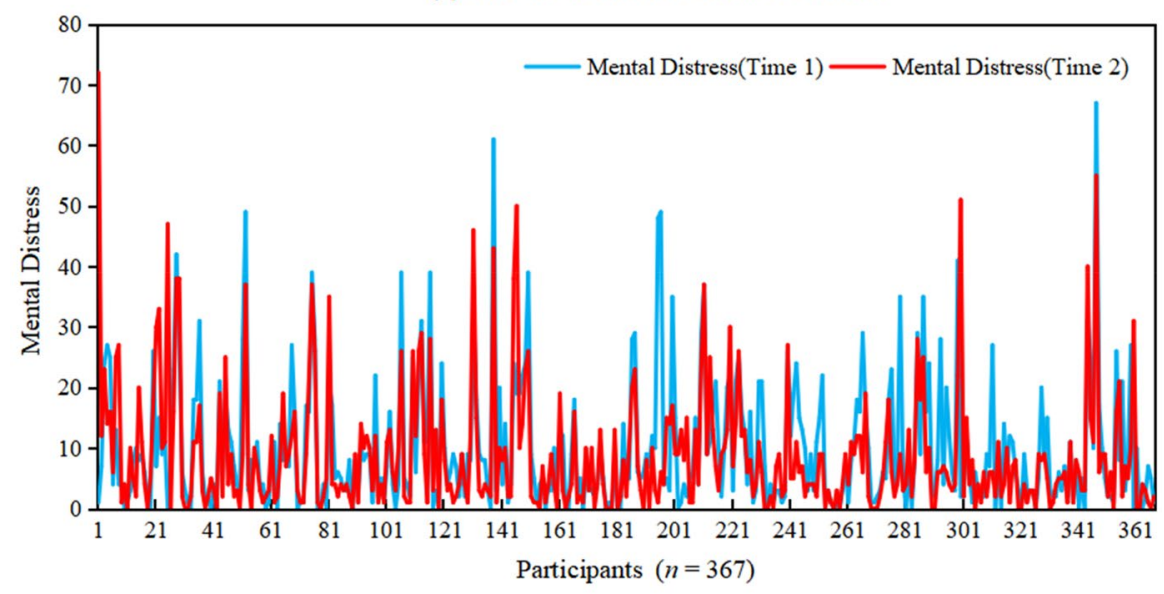

(b) Comparison Group: Mental Distress

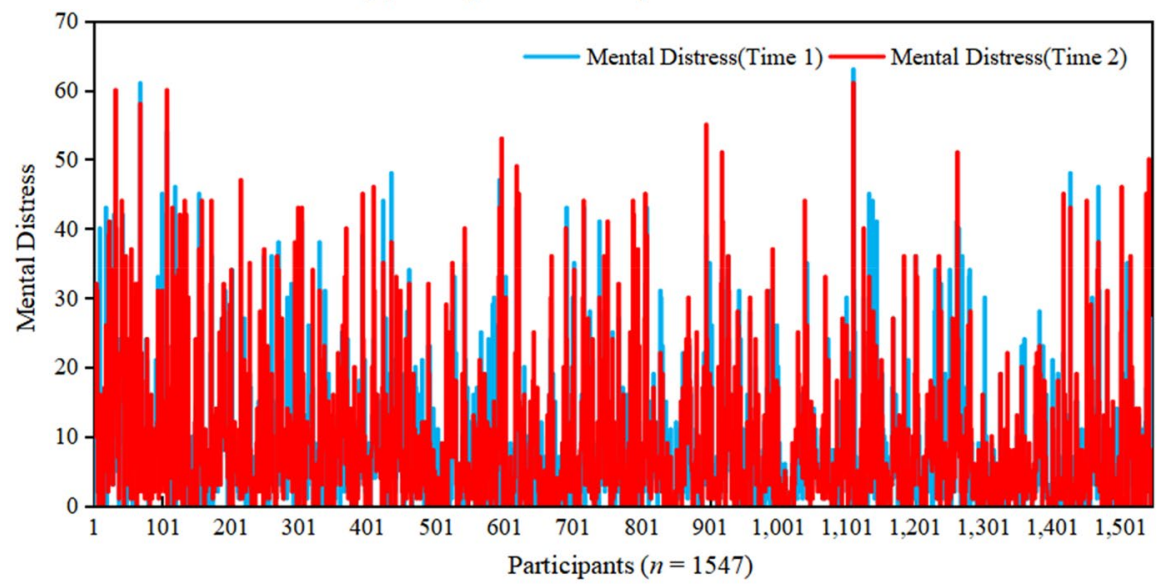

Fig. 6 Individual comparison on mental distress (GSI) at Time 1 (blue) and Time 2 (red) in Study 2 $(N=1914)$. Mental distress is a continuous variable ranging from 0 to 72 . (Color figure online)

\section{Discussion}

At Time 1, like in Study 1, health workers felt more mentally distressed, but also happier. After one month, health workers showed reduced mental distress, whereas the comparison group showed increased mental distress. Both groups showed increases in happiness. These changes in mental distress were partially mediated by happiness at Time 1 indicating that experiencing happiness concurrently with distress is related to lower distress in the long-term. 


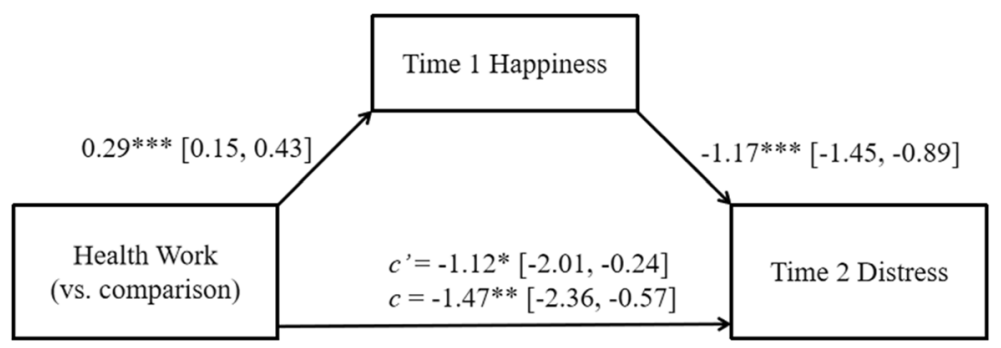

Fig. 7 The indirect effect of health work (vs. comparison group) on Time 2 distress via Time 1 happiness, adjusting for Time 1 distress $(N=1914$; Study 2). Ordinary least squares regression coefficients are unstandardized. Brackets beside the regression coefficients represent $95 \%$ confidence intervals. $* p<.050$, $* * p<.010, * * * p<.001$

\section{General discussion}

Humans are a uniquely prosocial species. They willingly help family, friends, and strangers, even when helping involves great personal risk. To wit, as COVID-19 began undermining health and economic stability across the globe, people answered the call to serve in hospitals, food banks, and manufacturing plants. Across two studies, in two countries, at different phases of the pandemic, we explored the emotional experience of helpers. Perhaps not surprisingly, helpers reported higher mental distress than comparison groups. However, corroborating past research on the benefits of prosocial behavior (Curry et al., 2018), helpers also reported higher happiness.

Although mental distress is negatively related to happiness, mental health and mental illness constitute two separate unipolar dimensions (Keyes, 2005), as do their hallmarks, positive and negative emotions (Watson et al., 1988). Thus, even during highly stressful situations, people can experience positive and negative emotions simultaneously, as the experience of stress does not negate the possibility of positive emotions (Folkman, 1997). Indeed, the helpers in our studies simultaneously reported higher average levels of distress and happiness. Importantly, we explored happiness alongside distress not to diminish the very real and severe distress our helpers reported, but to understand the full emotional landscape and to examine whether, in the context of a severe and sustained pandemic, positive emotions could serve as a resource for healing over time.

Given the extreme working conditions, it seems obvious why helping during the pandemic is associated with greater distress. However, why helping is also associated with greater happiness is less apparent. Helping may boost happiness by increasing self-esteem, meaning or purpose in life, and connectedness to others. First, participants randomly assigned to help others rated themselves higher on various positive personal characteristics (e.g., trustworthy, considerate, useful, kind; Williamson \& Clark, 1989). Similarly, Chinese health workers engaged in the care of patients with COVID-19 reported feeling proud that they were meeting the task at hand despite challenges (Liu et al., 2020). Thus, helping boosts positive perceptions of oneself (e.g., self-esteem), which is related to happiness (Lyubomirsky et al., 2006). Second, Chinese health workers engaged in the care of patients with 
COVID-19 reported fulfilling their sense of duty as health workers to assist in this pandemic (i.e., their purpose in life; Liu et al., 2020). Having a sense of meaning and purpose in life is highly related to happiness (Disabato et al., 2016; Steger et al., 2008) and was included in both of our studies as part of the happiness measure. Lastly, Chinese health workers reported a sense of camaraderie with their colleagues and increased social support from their loved ones (Liu et al., 2020). Thus, likely because of their position as helpers, Chinese health workers felt closer to their colleagues and to their personal support network, increasing feelings of connectedness, which are related to happiness (Ryan \& Deci, 2000).

Importantly, experiencing positive emotions during the stress process predicts better coping and more favorable psychological outcomes (Folkman, 2008; Fredrickson et al., 2003). Indeed, decreases in distress among health workers (and increases in distress among comparison group) from Time 1 to Time 2 were partially mediated by Time 1 happiness. Although both groups increased in happiness from Time 1 to Time 2, the higher happiness levels of health workers at Time 1 partially explained recovery from their previously higher levels of distress. Crucially, as health work was still related to lower distress after accounting for Time 1 happiness, there are factors bearing on distress that are unaccounted for in our model. For example, variations in psychological support in participants' workplaces or differences in financial or personal resources (e.g., social support) may also explain changes in distress over time.

\section{Limitations and future directions}

In both studies, we only captured moments in time in two countries during a pandemic that, as of this writing (January 2021), continues to rage in many countries. Study 1 data were collected in the United States at the end of March when infection rates were rising, but most people still did not comprehend the severity or potential length of this pandemic. Researchers would do well also to capture the mental distress and happiness of volunteers and non-volunteers in the United States now, as the financial, emotional, and physical tolls of the pandemic are better understood and have posed a prolonged threat. Study 2 data were collected mid-March (Time 1) as China's efforts to contain the virus were paying off and infections were leveling off, and mid-April (Time 2) as China lifted its 76-day lockdown on Wuhan, the epicenter of the pandemic. Thus, we captured mental distress and happiness among health workers as conditions were improving. Our results could have been different had we captured Chinese health workers' sentiments during the end of January or in February when the situation was at its worst. Similarly, although mental distress decreased among health workers from Time 1 to Time 2, it is possible that there were long-term mental health effects (e.g., post-traumatic stress disorder) that are not captured in the current data. Future studies would do well to explore the psychological outcomes of helpers and comparison groups over a longer period of time, as well as the personal circumstances (e.g., socioeconomic status) that may relate to greater costs or benefits. 
Importantly, our studies compared pre-existing groups (vs. randomly assigned groups) so we cannot assume that volunteerism or health work caused people to be happier or more distressed. Indeed, altruism is related to higher happiness (Krueger et al., 2001), so volunteers and health workers could have been happier than the comparison group before the pandemic. We do not have pre-pandemic levels of mental distress or happiness to know whether these differences among groups predated the pandemic (Caldas et al., 2021). Notably, the helpers in both studies were autonomously motivated to help (either by volunteering or engaging in their chosen profession). Thus, policy makers should not take these findings to mean that people involuntarily assigned to help during pandemic responses will reap happiness as a result (Weinstein \& Ryan, 2010).

In addition, given the widespread consequences of the pandemic, participants in our comparison groups were undoubtedly suffering effects of the pandemic. Thus, although their distress was not as high as the volunteers and health workers, their happiness could have been affected by being forced to stay home, fearing the pandemic, being deemed "non-essential," dealing with online education for their children, or losing their jobs. Given our correlational design, we cannot ascertain whether being able to help during the pandemic increased helpers' happiness or whether staying home decreased our comparison groups' happiness. Our framing largely focused on the experience of volunteers and health workers, but it is just as possible that the experiences of our comparison groups were driving these differences.

Our analyses focused on average levels of mental distress and happiness in our respective groups, but future research should explore different patterns within individuals. For example, some may experience extremely high levels of distress and low levels of happiness, some may experience high levels of both, and some may experience low levels of both. Follow-up work might address different emotional profiles and their predictors (e.g., does having greater social support predict high happiness alongside high distress among health workers?). Similarly, although exploring people's global conception of their happiness is instructive and gives a general sense of how people are feeling, a more fine-grained analysis of specific positive emotions would be helpful. For example, probably none of our health workers were going about their arduous days with feelings of high-arousal joy. More likely, our health workers caught moments of quiet reflection in which they felt proud of what they were contributing, content that a certain patient was strengthening, or moved by the generosity and bravery of their colleagues - all positive emotions that contribute to happiness. Exploring specific positive emotions may help future researchers better appreciate the nature of happiness amidst dire circumstances.

\section{Conclusions}

The current studies are a first step in understanding the emotional experience of helpers during the COVID-19 pandemic. Our results demonstrate that pandemic workers had the ability to experience happiness alongside inevitable stress, and that 
this happiness helped them alleviate the psychological strain from engaging in this vital but taxing work.

Supplementary Information The online version of this article (doi:https://doi.org/10.1007/s40167-02100100-1) contains supplementary material, which is available to authorized users.

Author contributions X.Z. and T.M. designed the studies; T.M. and X.Z. conducted the studies and analyzed the data; C.S., K.L., X.Z., and T.M. discussed conceptual and data analytic issues, and wrote the manuscript.

Funding This work was supported by the National Natural Science Foundation of China under Grant 31871095,71672169 and 71925005.

Data availability Upon request via email.

\section{Declarations}

Conflict of interest The authors declare that they have no conflict of interest.

Ethical approval Both studies were approved by the Department of Psychology, University of [BLINDED], and informed consent was obtained prior to participation.

\section{References}

Aknin, L. B., Hamlin, J. K., \& Dunn, E. W. (2012). Giving leads to happiness in young children. PLoS ONE, 7(6), e39211. https://doi.org/10.1371/journal.pone.0039211.

Alden, L. E., \& Trew, J. L. (2013). If it makes you happy: Engaging in kind acts increases positive affect in socially anxious individuals. Emotion, 13(1), 64-75. https://doi.org/10.1037/a0027761.

Bai, Y., Lin, C. C., Lin, C. Y., Chen, J. Y., Chue, C. M., \& Chou, P. (2004). Survey of stress reactions among health care workers involved with the SARS outbreak. Psychiatric Services, 55(9), 10551057. https://doi.org/10.1176/appi.ps.55.9.1055.

Caldas, M. P., Ostermeier, K., \& Cooper, D. (2021). When helping hurts: COVID-19 critical incident involvement and resource depletion in health care workers. Journal of Applied Psychology, 106(1), 29-47. https://doi.org/10.1037/apl0000850.

Chancellor, J., Margolis, S., Jacobs Bao, K., \& Lyubomirsky, S. (2018). Everyday prosociality in the workplace: The reinforcing benefits of giving, getting, and glimpsing. Emotion, 18(4), 507-517. https://doi.org/10.1037/emo0000321.

Cohen, M. (2014). Depression, anxiety, and somatic symptoms in older cancer patients: A comparison across age groups. Psycho-Oncology, 23(2), 151-157. https://doi.org/10.1002/pon.3383.

Curry, O. S., Rowland, L. A., Van Lissa, C. J., Zlotowitz, S., McAlaney, J., \& Whitehouse, H. (2018). Happy to help? A systematic review and meta-analysis of the effects of performing acts of kindness on the well-being of the actor. Journal of Experimental Social Psychology, 76, 320-329. https://doi. org/10.1016/j.jesp.2018.02.014.

Derogatis, L. R. (2001). BSI 18, Brief Symptom Inventory 18: Administration, scoring and procedures manual. NCS Pearson, Inc.

Disabato, D. J., Goodman, F. R., Kashdan, T. B., Scott, J. L., \& Jarden, A. (2016). Different types of wellbeing? A cross-cultural examination of hedonic and eudaimonic well-being. Psychological Assessment, 28(5), 471-482. https://doi.org/10.1037/pas0000209.

Folkman, S. (1997). Positive psychological states and coping with severe stress. Social Science \& Medicine, 45(8), 1207-1221. https://doi.org/10.1016/s0277-9536(97)00040-3.

Folkman, S. (2008). The case for positive emotions in the stress process. Anxiety, Stress, \& Coping, 21(1), 3-14. https://doi.org/10.1080/10615800701740457. 
Fredrickson, B. L., Tugade, M. M., Waugh, C. E., \& Larkin, G. R. (2003). What good are positive emotions in crises? A prospective study of resilience and emotions following the terrorist attacks on the United States on September 11th, 2001. Journal of Personality and Social Psychology, 84(2), 365-376. https://doi.org/10.1037//0022-3514.84.2.365.

Hayes, A. F. (2018). Introduction to mediation, moderation, and conditional process analysis: A regression-based approach (2nd ed.). Guilford Press.

Keyes, C. L. M. (2005). Mental illness and/or mental health? Investigating axioms of the complete state model of health. Journal of Consulting and Clinical Psychology, 73(3), 539-548. https:// doi.org/10.1037/0022-006X.73.3.539.

Krueger, R. F., Hicks, B. M., \& McGue, M. (2001). Altruism and antisocial behavior: Independent tendencies, unique personality correlates, distinct etiologies. Psychological Science, 12(5), 397402. https://doi.org/10.1111/1467-9280.00373.

Lai, J., Ma, S., Wang, Y., Cai, Z., Hu, J., Wei, N., Wu, J., Du, H., Chen, T., Li, R., Tan, H., Kang, L., Yao, L., Huang, M., Wang, H., Wang, G., Liu, Z., \& Hu, S. (2020). Factors associated with mental health outcomes among health care workers exposed to Coronavirus disease 2019. JAMA Network Open, 3(3), e203976. https://doi.org/10.1001/jamanetworkopen.2020.3976.

Layous, K., Lee, H., Choi, I., \& Lyubomirsky, S. (2013). Culture matters when designing a successful happiness-increasing activity. Journal of Cross-Cultural Psychology, 44(8), 1294-1303. https:// doi.org/10.1177/0022022113487591.

Lee, A. M., Wong, J. G., McAlonan, G. M., Cheung, V., Cheung, C., Sham, P. C., Chu, C. M., Wong, P. C., Tsang, K. W., \& Chua, S. E. (2007). Stress and psychological distress among SARS survivors 1 year after the outbreak. The Canadian Journal of Psychiatry, 52(4), 233-240. https://doi. org/10.1177/070674370705200405.

Lee, S. M., Kang, W. S., Cho, A., Kim, T., \& Park, J. K. (2018). Psychological impact of the 2015 MERS outbreak on hospital workers and quarantined hemodialysis patients. Comprehensive Psychiatry, 87, 123-127. https://doi.org/10.1016/j.comppsych.2018.10.003.

Liu, Q., Luo, D., Haase, J. E., Guo, Q., Wang, X. Q., Liu, S., Xia, L., Zhongchun, L., Jiong, Y., \& Yang, B. X. (2020). The experiences of health-care providers during the COVID-19 crisis in China: A qualitative study. Lancet Global Health, 8, e790-e798. https://doi.org/10.1016/S2214109X(20)30204-7.

Lyubomirsky, S., \& Lepper, H. (1999). A measure of subjective happiness: Preliminary reliability and construct validation. Social Indicators Research, 46, 137-155. https://doi.org/10.1023/A:10068 24100041.

Lyubomirsky, S., Sheldon, K. M., \& Schkade, D. (2005). Pursuing happiness: The architecture of sustainable change. Review of General Psychology, 9(2), 111-131. https://doi.org/10.1037/10892680.9.2.111.

Lyubomirsky, S., Tkach, C., \& Dimatteo, M. R. (2006). What are the differences between happiness and self-esteem? Social Indicators Research, 78, 363-404. https://doi.org/10.1007/ s11205-005-0213-y.

Maslach, C., Schaufeli, W. B., \& Leiter, M. P. (2001). Job burnout. Annual Review of Psychology, 52(1), 397-422. https://doi.org/10.1146/annurev.psych.52.1.397.

Maunder, R., Hunter, J., Vincent, L., Bennett, J., Peladeau, N., Leszcz, M., Sadavoy, J., Verhaeghe, L. M., Steinberg, R., \& Mazzulli, T. (2003). The immediate psychological and occupational impact of the 2003 SARS outbreak in a teaching hospital. Canadian Medical Association Journal, 168(10), 1245-1251. https://doi.org/10.1001/jama.289.18.2432.

Meachen, S., Hanks, R. A., Millis, S. R., \& Rapport, L. J. (2008). The reliability and validity of the Brief Symptom Inventory-18 in persons with traumatic brain injury. Archives of Physical Medicine and Rehabilitation, 89(5), 958-965. https://doi.org/10.1016/j.apmr.2007.12.028.

Mongrain, M., Chin, J. M., \& Shapira, L. B. (2011). Practicing compassion increases happiness and self-esteem. Journal of Happiness Studies, 12(6), 963-981. https://doi.org/10.1007/ s10902-010-9239-1.

National Health Commission of the People's Republic of China (2020). Fighting against the epidemic: Live up to the "Post-90s" anti-epidemic youth. Retrieved from 0d7d2c49218e97c3e4d772b6c6. shtml.

Nelson, S. K., Della Porta, M. D., Bao, J., Lee, K., Choi, H. C., I., \& Lyubomirsky, S. (2014). 'It' s up to you': Experimentally manipulated autonomy support for prosocial behavior improves well-being in two cultures over six weeks. The Journal of Positive Psychology, 10(5), 463-476. https://doi.org/10. 1080/17439760.2014.983959. 
Otake, K., Shimai, S., Tanaka-Matsumi, J., Otsui, K., \& Fredrickson, B. L. (2006). Happy people become happier through kindness: A counting kindnesses intervention. Journal of Happiness Studies, 7(3), 361-375. https://doi.org/10.1007/s10902-005-3650-z.

Petkus, A. J., Gum, A. M., Small, B., Malcarne, V. L., Stein, M. B., \& Wetherell, J. L. (2010). Evaluation of the factor structure and psychometric properties of the Brief Symptom Inventory-18 with homebound older adults. International Journal of Geriatric Psychiatry, 25(6), 578-587. https://doi. org/10.1002/gps.2377.

Pressman, S. D., Kraft, T. L., \& Cross, M. P. (2014). It's good to do good and receive good: The impact of a 'pay it forward' style kindness intervention on giver and receiver well-being. The Journal of Positive Psychology, 10(4), 293-302. https://doi.org/10.1080/17439760.2014.965269.

Rietschlin, J. (1998). Voluntary association membership and psychological distress. Journal of Health and Social Behavior, 39(4), 348-355. https://doi.org/10.2307/2676343.

Ryan, R. M., \& Deci, E. L. (2000). Self-determination theory and the facilitation of intrinsic motivation, social development, and well-being. American Psychologist, 55(1), 68-78. https://doi.org/10.1037// 0003-066X.55.1.68.

Ryff, C. D. (1989). Happiness is everything, or is it? Explorations on the meaning of psychological wellbeing. Journal of Personality and Social Psychology, 57(6), 1069-1081. https://doi.org/10.1037/ 0022-3514.57.6.1069.

Steger, M. F., Kashdan, T. B., \& Oishi, S. (2008). Being good by ng good: Daily eudaimonic activity and well-being. Journal of Research in Personality, 42, 22-42. https://doi.org/10.1016/j.jrp.2007. 03.004.

Thoits, P. A., \& Hewitt, L. N. (2001). Volunteer work and well-being. Journal of Health and Social Behavior, 42(2), 115-131. https://doi.org/10.2307/3090173.

Wang, K. T., Heppner, P. P., Fu, C.-C., Zhao, R., Li, F., \& Chuang, C.-C. (2012). Profiles of acculturative adjustment patterns among Chinese international students. Journal of Counseling Psychology, 59(3), 424-436. https://doi.org/10.1037/a0028532.

Wang, J., Kelly, B. C., Liu, T., Zhang, G., \& Hao, W. (2013). Factorial structure of the Brief Symptom Inventory (BSI)-18 among Chinese drug users. Drug and Alcohol Dependence, 133(2), 368-375. https://doi.org/10.1016/j.drugalcdep.2013.06.017.

Wang, C.-C. D., \& Mallinckrodt, B. (2006). Acculturation, attachment, and psychosocial adjustment of Chinese/Taiwanese international students. Journal of Counseling Psychology, 53(4), 422-433. https://doi.org/10.1037/0022-0167.53.4.422.

Watson, D., Clark, L. A., \& Carey, G. (1988). Positive and negative affectivity and their relation to anxiety and depressive disorders. Journal of Abnormal Psychology, 97(3), 346-353. https://doi.org/10. 1037//0021-843x.97.3.346.

Weinstein, N., \& Ryan, R. M. (2010). When helping helps: Autonomous motivation for prosocial behavior and its influence on well-being for the helper and recipient. Journal of Personality and Social Psychology, 98(2), 222-244. https://doi.org/10.1037/a0016984.

Williamson, G. M., \& Clark, M. S. (1989). Providing help and desired relationship type as determinants of changes in moods and self-evaluations. Journal of Personality and Social Psychology, 56(5), 722-734. https://doi.org/10.1037//0022-3514.56.5.722.

World Economic Forum. (2020). More than 170,000 volunteers to help UK fight coronavirus.

Publisher's note Springer Nature remains neutral with regard to jurisdictional claims in published maps and institutional affiliations. 